IRA-International Journal of Technology \& Engineering ISSN 2455-4480

Proceedings of the

International Conference on Science \& Engineering for Sustainable Development (2017)

Pg. no.105-112

Published by: Institute of Research Advances https://research-advances.org/index.php/IRAJTE

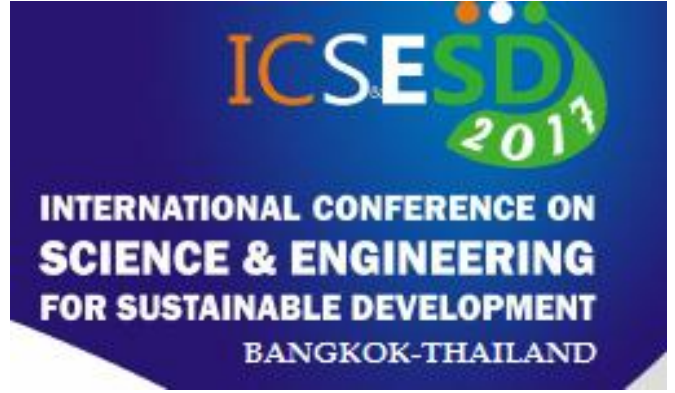

\title{
Experimental Investigation of Heat Transfer Rate Using Twisted Tape with Elliptical Holes
}

\author{
K. R. Gawande ${ }^{1}$, A. V. Deshmukh*2 \\ ${ }^{1}$ M. Tech., Asst. Professor in Department of Mechanical Engineering, \\ ${ }^{2}$ PG Student (Thermal Engg.), Department of Mechanical Engineering, Dr. Rajendra \\ Gode Institute of Technology and Research.
}

Type of Review: Originality Check \& Peer Review under the responsibility of the Scientific Committee of the Conference and The Institution of Engineers (India). DOI: http://dx.doi.org/10.21013/jte.ICSESD201711

\section{How to cite this paper:}

Gawande, K., Deshmukh, A. (2017). Experimental Investigation of Heat Transfer Rate Using Twisted Tape with Elliptical Holes. Proceedings of the International Conference on Science \& Engineering for Sustainable Development (2017), 105-112. doi: http://dx.doi.org/10.21013/ite.ICSESD201711

(C) International Conference on Science \& Engineering for Sustainable Development\& The Institution of Engineers (India).

\section{(cc) BY-NC}

This work is licensed under a Creative Commons Attribution-Non Commercial 4.0 International License subject to proper citation to the publication source of the work.

Disclaimer: The conference papers as published by the Institute of Research Advances (IRA) are the views and opinions of their respective authors and are not the views or opinions of the IRA. The IRA disclaims of any harm or loss caused due to the published content to any party. 


\section{ABSTRACT}

An experimental investigation was carried for measuring tube-side heat transfer coefficient, friction factor, heat transfer enhancement efficiency of water for turbulent flow in a circular tube fitted with rectangular-cut twisted tape insert. A copper tube of $26.6 \mathrm{~mm}$ internal diameter and $30 \mathrm{~mm}$ outer diameter and $900 \mathrm{~mm}$ test length was used. A stainless steel rectangular-cut twisted tape insert of 5.25 twist ratio was inserted into the smooth tube. The rectangular cut had $8 \mathrm{~mm}$ depth and $14 \mathrm{~mm}$ width. A uniform heat flux condition was created by wrapping nichrome wire around the test section and fiber glass over the wire. Outer surface temperatures of the tube were measured at 5 different points of the test section by T-type thermocouples. Two thermometers were used for measuring the bulk temperatures. At the outlet section the thermometer was placed in a mixing box. The Reynolds numbers were varied in the range 10000-19000 with heat flux variation 14 to $22 \mathrm{~kW} / \mathrm{m} 2$ for smooth tube, and 23 to $40 \mathrm{~kW} / \mathrm{m} 2$ for tube with insert. Nusselt numbers obtained from smooth tube were compared with Gnielinski correlation and errors were found to be in the range of $-6 \%$ to $-25 \%$ with r.m.s. value of $20 \%$. At comparable Reynolds number, Nusselt numbers in tube with rectangular-cut twisted tape insert were enhanced by 2.3 to 2.9 times at the cost of increase of friction factors by 1.4 to 1.8 times compared to that of smooth tube. Heat transfer enhancement efficiencies were found to be in the range of 1.9 to 2.3 and increased with the increase of Reynolds number.

\section{Introduction}

To improve the performance of heat exchanging devices for reducing material cost and surface area and decreasing the difference for heat transfer thereby for reducing external irreversibility, lot of techniques have been used. Among different passive means to increase heat transfer coefficient, twisted tape inserts are promising. The secondary flow (swirl flow) generated by twisted tape effects fluid flow across the tape-partitioned tube, promotes greater mixing and higher heat transfer coefficients. Experimental investigation of heat transfer and friction factor characteristics in a double pipe heat exchanger fitted with regularly spaced twisted tape elements were studied by Eiamsa-ard et al., 2006. Heat transfer, friction factor and heat transfer enhancement efficiency characteristics in a circular tube fitted with conical-ring turbulators and a twisted-tape swirl generator have been investigated experimentally by Promvonge and Eiamsa-ard, 2007. Influences of insertion of wire coils in conjunction with twisted tapes on heat transfer and friction characteristics in a circular tube using air as the test fluid were experimentally investigated by Promvonge, 2008. Eiamsa-ard et al., 2009, experimentally investigated the influences of the tube with short-length twisted tape inserts on the heat transfer, friction factor, and heat transfer enhancement efficiency. Heat transfer, friction factor and heat transfer enhancement efficiency behaviors in a tube equipped with the combined devices between the twisted tape and constant/periodically varying wire coil pitch ratio were experimentally investigated by Eiamsa-ard et al., 2010a. Eiamsa-ard et al., 2010b experimentally determined the influences of twin-counter/co-twisted tapes on heat transfer rate, friction factor, and heat transfer enhancement efficiency. Heat transfer, flow friction and heat transfer enhancement efficiency characteristics in a tube fitted with delta-winglet twisted tape, using water as working fluid were investigated experimentally by Eiamsa-ard et al., 2010c. Murugesan et al., 2010, experimentally investigated heat transfer, friction factor, and heat transfer enhancement efficiency characteristics of a double pipe heat exchanger fitted with square-cut twisted tapes. Shabanian et al., 2011 reported the experimental and computational fluid dynamics modeling studies on heat transfer, friction factor and heat transfer enhancement efficiency of an air cooled heat exchanger equipped with classic and jagged twisted tape. 
The scope of the present work is to experimentally investigate the tube side heat transfer and friction factor of a circular tube fitted with twisted tape with elliptical holes insert. Data are compared with smooth tube heat transfer and friction values and the values of heat transfer enhancement efficiency are reported.

\section{Experimental Set Up}

The apparatus consists of a centrifugal blower unit fitted with a circular tube, which is connected to the test tube located in horizontal orientation. Flexi glass heater encloses the test section to a whole length of $1 \mathrm{~m}$. Input to heater is given through rheostat. Four thermo couples $\mathrm{T}_{1}, \mathrm{~T}_{2}, \mathrm{~T} 3$ and $\mathrm{T}_{4}$ at an equal distance of $15 \mathrm{~cm}$ from the origin of the heating zone are embedded on the walls of the tube and one thermocouple is placed in the air stream at the exit $\left(\mathrm{T}_{5}\right)$ of the test section to measure the temperature of flowing air. The digital device Multimeter is used to display the temperature measured by thermocouple at various position. The temperature measured by instrument is in ${ }^{0} \mathrm{C}$. The test tube of $3 \mathrm{~mm}$ thickness is used for experimentation. A $\mathrm{U}$ tube manometer measures the pressure drop across the test section filled with water. The pipe system consists of a valve, which controls the airflow rate through it and an orifice meter to find the volume flow rate of air through the system. The diameter of the orifice is $.0125 \mathrm{~m}$ and coefficient of discharge is 0.61 . The two pressure tapings of the orifice meter are connected to a water Utube manometer to indicate the pressure difference between them. Display unit is a digital Multimeter used to indicate temperature indicator. The circuit is designed for a load voltage of $0-100 \mathrm{~V}$; with a maximum current of $10 \mathrm{~A}$. Difference in the levels of manometer fluid represents the variations in the flow rate of air. The velocity of airflow in the tube is measured with the help of orifice plate and the water manometer fitted on board.

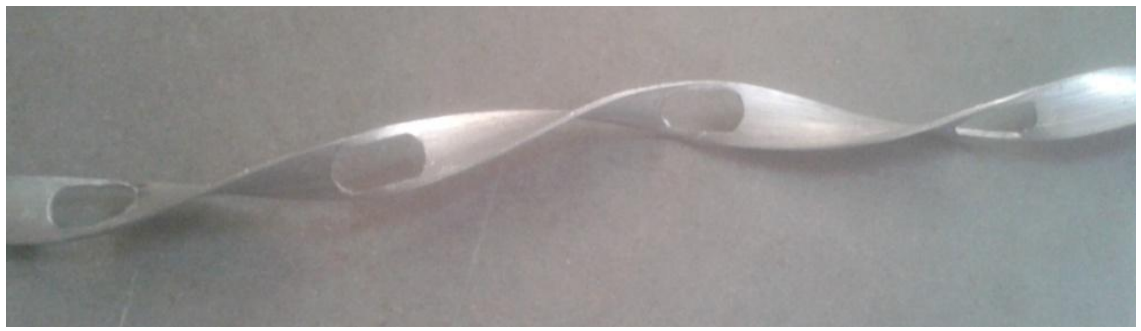

Fig: Twisted Tape with elliptical hole

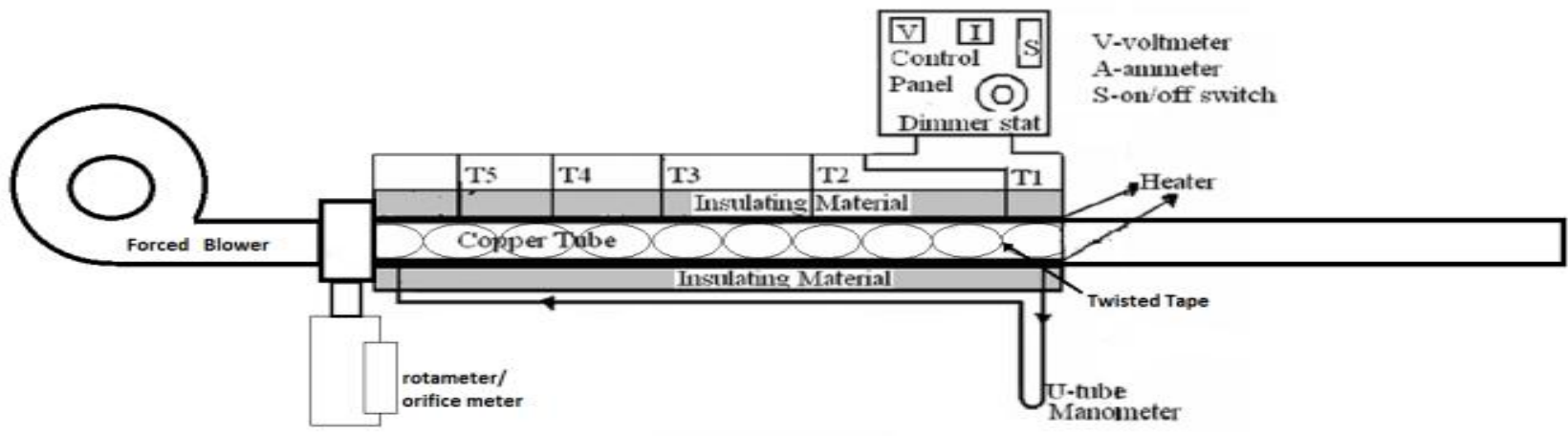

Fig: Schematic diagram of the Experimental Set-up 


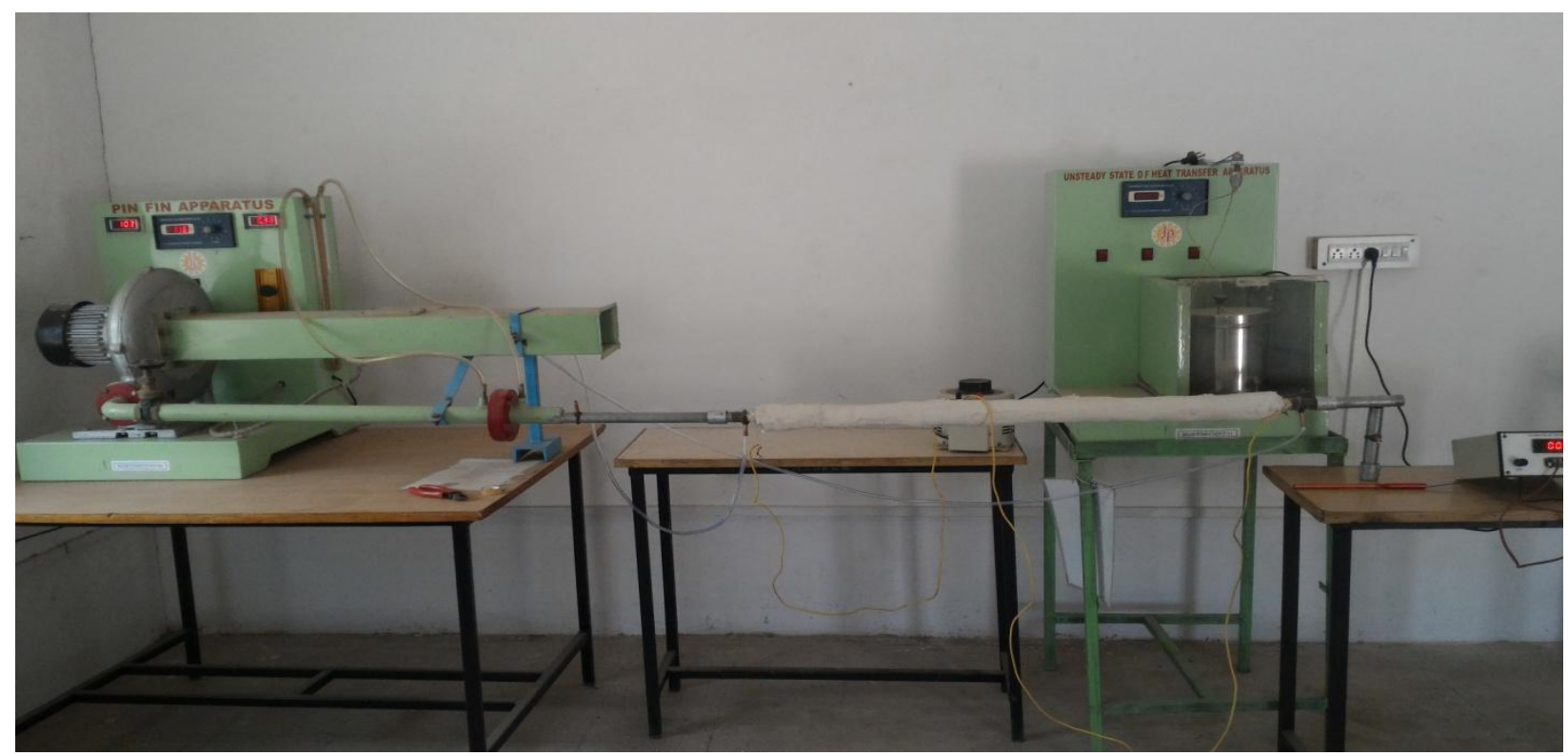

Fig: Experimental Set-up in LAB

\section{Data Reduction}

The data reduction of the measured results is summarized in the following procedures:

$T_{s}=\frac{T_{1}+T_{2}+T_{3}+T_{4}}{4}$

$T_{b}=\frac{T_{a}+T_{5}}{2}$

Discharge of Air:

$$
\mathrm{Q}=\mathrm{Cd} \frac{\mathrm{a}_{1} \mathrm{a}_{2} \sqrt{{ }^{2 \mathrm{gH} \frac{\rho_{\mathrm{w}}}{\rho_{\mathrm{a}}}}}}{\sqrt{\mathrm{a}_{1}^{2}-\mathrm{a}_{2}^{2}}}
$$

Mass flow rate of air $=Q \times \rho_{a}$

Velocity $V=\frac{m}{\rho a_{1}}$

Cross sectional Area:

$a_{1}=\frac{\pi}{4} \mathrm{di}^{2}$

Reynolds Number:

$$
R e=\frac{\rho v D}{\mu}
$$

Where $\Delta T=T_{a}-T_{5}=T_{s}-T_{b}$

$$
Q=m C p(\Delta T)=h A s(\Delta T)
$$

Heat transfer coefficient: 
Experimental Nusselt number:

$$
h=\frac{m C_{p}\left(T_{a}-T_{5}\right)}{A_{s}\left(T_{s}-T_{b}\right)}
$$

$$
N u=\frac{h D_{i}}{k}
$$

Theoretical Nusselt number by Dittus Boelter equation

$$
N u_{0}=0.0023 R e^{0.8} p r^{0.4}
$$

Blasius equation of Turbulent Flow

$$
f=0.079 R e^{-0.25}
$$

Enthalpy change $=m C_{p}\left(T_{o}-T_{i}\right)$

$\mathrm{Q}=m C p(\Delta T)=h \operatorname{As}\left(\Delta T_{l m}\right)$

Where $T_{l m}=\frac{\left(T_{w}-T_{i n}\right)-\left(T_{w}-T_{o}\right)}{\ln \frac{\left(T_{w}-T_{i n}\right)}{\left(T_{w}-T_{o}\right)}}$

Thermal performance factor

Pressure drop

$$
T P F=\frac{\frac{N u}{N u 0}}{\left(\frac{f}{f 0}\right)^{1 / 3}}
$$

Enhancement Efficiency

$$
\Delta p=\frac{f l \rho v^{2}}{2 D}
$$

$$
\eta=\frac{h}{h 0}
$$

\section{Numerical Results and Discussion 1 Heat Transfer}

The results of heat transfer characteristics are presented for turbulent airflows. Two different twisted tape, one is without hole and another is with elliptical hole were compared with the plain tube. Several parameters were used for the purpose of heat transfer characteristics comparison. The average surface Nusselt number, average heat transfer coefficient and thermal performance parameter based on the Nusselt number ratio and pressure drop across the channel were used for heat transfer characteristics comparison.

The surface averaged Nusselt number is compared for all the three tubes: The Plain tube, the tube with twisted tape without hole and the tube with the twisted tape with elliptical hole. The surface averaged Nusselt numbers for the plain tube $\mathrm{Nu}_{0}$ are taken as baseline data for comparison. The Nusselt number 
ratio $\mathrm{Nu} / \mathrm{Nu}_{0}$ comparing surface averaged Nusselt number of twisted tape and surface averaged Nusselt number of plain tube are plotted against the Reynolds number range studied.

When compared with the available literature for use of the twisted tape in the turbulent flow regime, it can be seen that the ratios $\mathrm{Nu} / \mathrm{Nu}_{0}$ have better levels of heat transfer augmentation for the high Reynolds number range.It can be seen that the values $\mathrm{Nu} / \mathrm{Nu}_{0}$ decrease with increasing Reynolds number for both the twisted tape without hole and twisted tape with elliptical hole. For twisted tape with elliptical hole it will remain almost constant. It can also be seen that the twisted tape with elliptical hole has higher $\mathrm{Nu} / \mathrm{Nu}_{0}$ values than the twisted tape without elliptical hole for a corresponding Reynolds number. However the Nusselt number values for both the twisted tape were greater than the plain tube irrespective of Reynolds number.

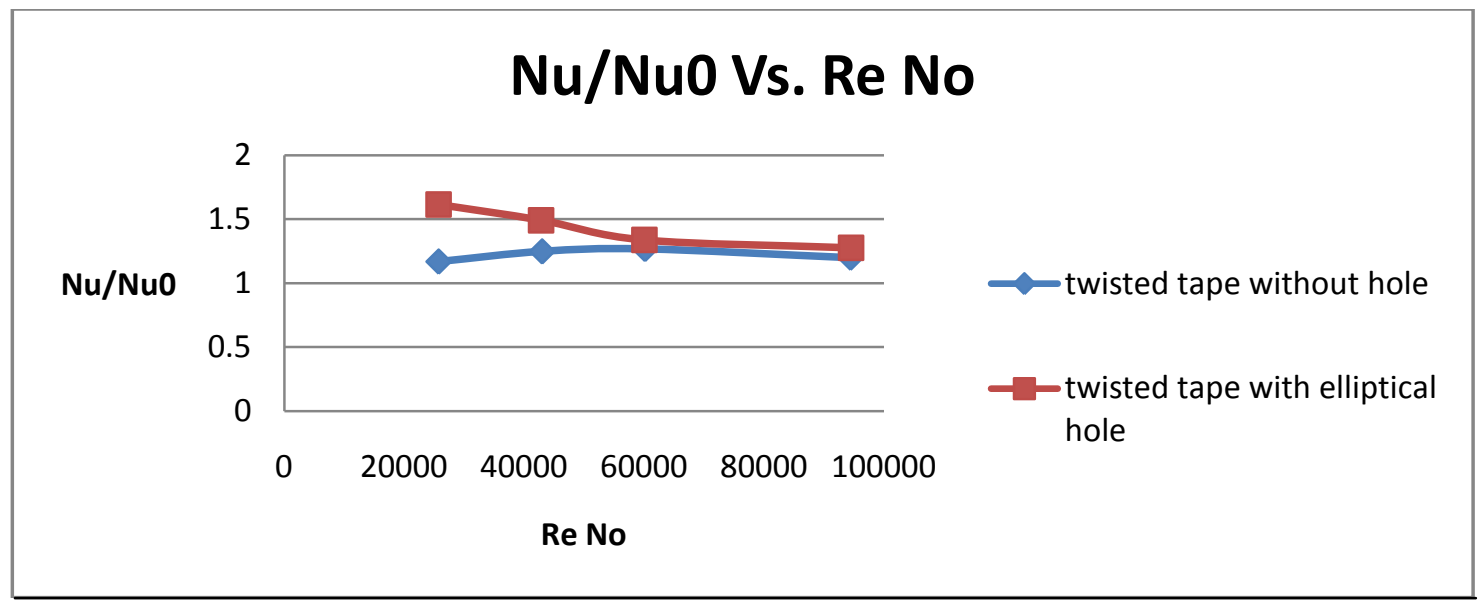

Fig.4.1:Comparison of Avg. Nusselt number of twisted tape without hole and twisted tape with hole Vs.

Reynolds number

Over the studied Reynolds number range, twisted tape without hole numerically shows slightly higher $\mathrm{Nu}$ values than the plain tube; whereas the twisted tape with hole show distinctively higher $\mathrm{Nu}$ values than the plain tubes numerically as well experimentally. For the twisted tape with hole Nusselt number is about 30 to $40 \%$ higher than the plain tube within the Reynolds number range of 25,000 to 95,000 . It is found that, over the studied Reynolds number range reasonably good agreements between the experimental and numerical $\mathrm{Nu}$ values have been achieved for the plain tube and twisted tape without hole and twisted tape with hole with average deviations of $8 \%$ to $10 \%$ respectively.

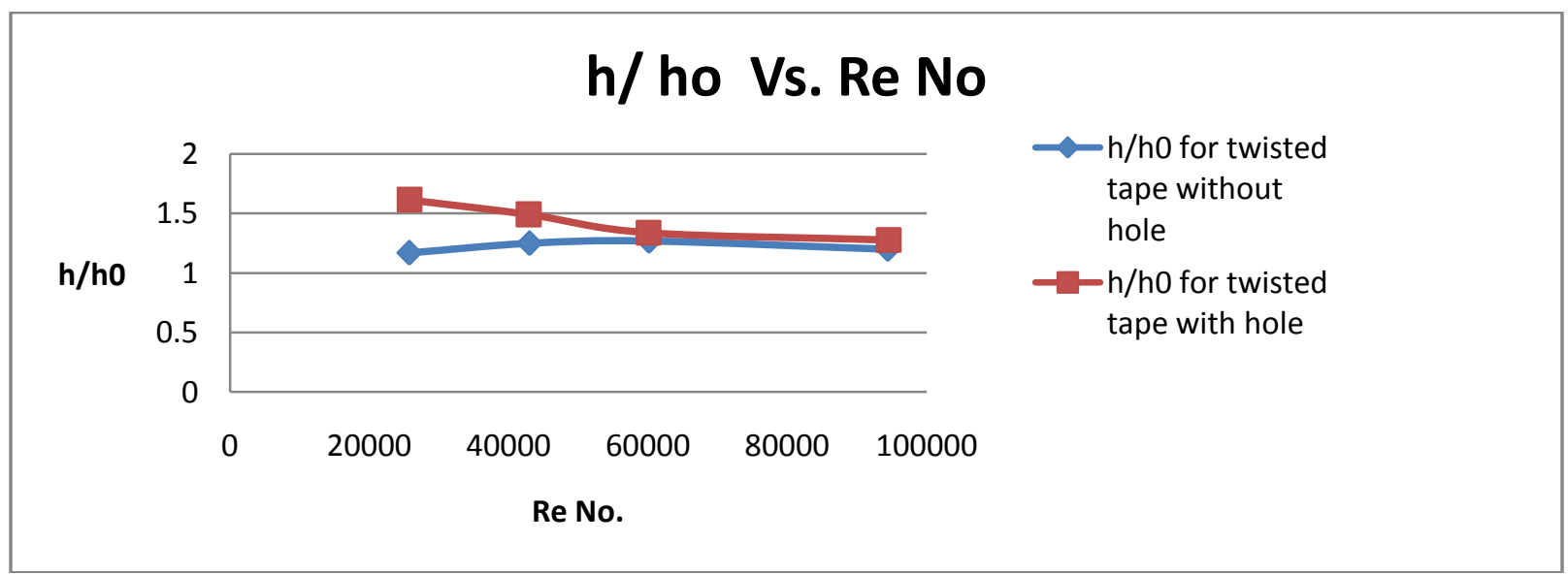


Fig.4.2. Avg. heat transfer coefficient for twisted tape without hole and twisted tape with hole Vs. Reynolds number

The heat transfer coefficient can be calculated from the thermal conductivity of the sworking fluid and the Nusselt number. Like the Nusselt number comparisons, the average heat transfer coefficient $\mathrm{ratios} h / \mathrm{h}_{0}$ with respect to the baseline data at the interface are plotted for both the twisted tape with hole and twisted tape without hole. The $\mathrm{h} / \mathrm{h} 0$ Plot show same pattern as the Nu/Nu0 plot. The h/h0 Plot of twisted tape with hole case is higher than the twisted tape without hole case.

\section{Conclusion and Summary}

This study focused on investigating whether the use of twisted tape with elliptical hole can enhance heat transfer characteristics for a circular tube. Two types of twisted tapes were tested for four different Reynolds numbers ranging from 25000 to 95000 . The twist geometry kept constant. The experimentation is carried out for both twisted tape without hole and twisted tape with hole which gives the good heat transfer enhancement.

1. The measurements are in good agreement with each other. The maximum error between the averaged experimental heat transfer enhancements with numerically predicted enhancement is $25 \%$.

2. Nu no increases about 28 to $30 \%$ in twisted tape without hole, and by 47 to $60 \%$ in twisted tape with hole. Variations in experimental values are because of manufacturing and measuring errors.

3. Enhancement efficiency obtains by twisted tape with hole experimentally about 2 to $4 \%$ greater than plain tube.

4. As the friction factor goes on decreasing as Re no increases. Experimentally for highest values of Re no it shows less deviation.

\section{References}

[1] Sh. Ghadirijafarbeiglooa, A. H. Zamzamianb, M. Yaghoubic, 3-D numerical simulation of heat transfer and turbulent flow in a receiver tube of solar parabolic trough concentrator with louvered twisted-tape inserts, Energy Procedia 49 ( 2014 ) 373 - 380

[2] Bodius Salam, Sumana Biswas, Shuvra Saha, Muhammad Mostafa K Bhuiya, Heat transfer enhancement in a tube using rectangular-cut twisted tape insert, Procedia Engineering 56 (2013) $96-103$.

[3]P. Ferroni , R.E. Block , N.E. Todreas, A.E. Bergles, Experimental evaluation of pressure drop in round tubes provided with physically separated, multiple, short-length twisted tapes, Experimental Thermal and Fluid Science 35 (2011) 1357-1369.

[4] Paisarn Naphon, Heat transfer and pressure drop in the horizontal double pipes with and without twisted tape insert, International Communications in Heat and Mass Transfer 33 (2006) $166-175$

[5]Shyy Woei Chang *, Tsun Lirng Yang, Jin Shuen Liou., Heat transfer and pressure drop in tube with broken twisted tape insert, Experimental Thermal and Fluid Science 32 (2007) 489-501

[6]K. Nanan , K. Yongsiri , K. Wongcharee, C. Thianpong, S. Eiamsa-ard , Heat transfer enhancement by helically twisted tapes inducing co- and Counter-swirl flows, International Communications in Heat and Mass Transfer 46 (2013) 67-73

[7]S. Eiamsa-ard, P. Somkleang, C. Nuntadusit, C. Thianpong, Heat transfer enhancement in 
tube by inserting uniform/non-uniform twisted-tapes with alternate axes: Effect of rotated-axis length, Applied Thermal Engineering 54 (2013) 289-309.

[8]Halit Bas, Veysel Ozceyhan, Heat transfer enhancement in a tube with twisted tape inserts placed separately from the tube wall, Experimental Thermal and Fluid Science 41 (2012) 51-58 